(อ) OPEN ACCESS

${ }^{1}$ Headache Group, Department of Basic and Clinical Neuroscience, King's College London, London, UK

${ }^{2}$ Department of Neurology, Hull Royal Infirmary, Hull, UK

${ }^{3}$ NIHR-Wellcome Trust King's Clinical Research Facility, SLaM Biomedical Research Centre, King's College Hospital, London, UK

\section{Correspondence to} Professor Peter I Goadsby, Wellcome Foundation Building, King's College Hospital, London, SE5 9PJ, UK; peter.goadsby@ kcl.ac.uk

Accepted 18 March 2019 Published Online First

5 July 2019

\title{
Managing cluster headache
}

\author{
Diana Y Wei (D) ,' Modar Khalil, ${ }^{1,2}$ Peter J Goadsby (D) 1,3
}

\begin{abstract}
Cluster headache is a neurological disorder that presents with unilateral severe headache associated with ipsilateral cranial autonomic symptoms. Cluster headache attacks often occur more than once a day, and typically manifesting in bouts. It has a point prevalence of 1 in 1000 and is the most common trigeminal autonomic cephalalgia. This article aims to guide general neurologists to an accurate diagnosis and practical management options for cluster headache patients.
\end{abstract}

\section{INTRODUCTION}

Cluster headache is a primary headache disorder and is the most common of the trigeminal autonomic cephalalgias ${ }^{1}$. It affects approximately 1 in 1000 of the population. A neurologist working in a district general hospital and regional neuroscience centre might see 4-11 cases of trigeminal autonomic cephalalgia per year. ${ }^{2}$ Most patients with cluster headache have a delayed diagnosis and will have seen three general practitioners before being referred to neurology services, some having been to colleagues in dentistry or otorhinolaryngology. ${ }^{3}$ While the diagnosis is usually straightforward, the management options are very different from that of migraine, the most common primary headache in neurology, and options are in a state of flux.

\section{CLINICAL DIAGNOSIS}

As with most neurological conditions, and certainly with all primary headache disorders, the diagnosis of cluster headache relies on an accurate history. The International Classification of Headache Disorders-3rd edition outlines the criteria for diagnosis, and although developed for research purposes, it remains a useful practical guide. There are always challenging cases that fall outside any criteria in neurological practice and these will be covered later in this article.

Attack phenotype: Patients describe a cluster headache attack as an intense and severe strictly unilateral pain, typically in the supraorbital, retro-orbital, temporal regions and arising from deep within. It has been said anecdotally, and recently studied, ${ }^{4}$ that patients describe it as their worst ever headache, using comparisons such as childbirth, fractures and renal stones. The pain ramps up quite quickly once it starts and typically remains for 15-180 min when untreated. During this time, patients are agitated and restless, preferring to rock in a sitting position, pace, fidget and push their hands into the area of most pain. Cluster headache attacks can occur once every other day in the start of a bout and increase to up to eight times a day. The attacks can have a circadian pattern with a nocturnal preference. They are usually associated with prominent cranial autonomic symptoms: lacrimation, conjunctival injection, nasal symptoms, aural fullness, periorbital swelling, ptosis or miosis, which are ipsilateral to the pain. ${ }^{5}$

Attack patterns: Cluster headache is subdivided into episodic and chronic cluster headache depending on the duration between attacks. Patients with episodic cluster headache have 'bouts', describing when they have a cluster of attacks. These bouts tend to last 6-12 weeks and often have a circannual pattern, with more attacks in the spring or autumn. Patients are deemed to have episodic cluster headache if the break between the bouts lasts longer than 3 months, while not taking a preventive treatment. Patients have bouts of attacks with breaks of less than 3 months between are classified as having chronic cluster headache. ${ }^{1}$ This differentiation, although somewhat arbitrary, has important management implications. When in bout, cluster headache attacks can be triggered by alcohol, ${ }^{6}$ ${ }^{7}$ food containing nitrates, nitroglycerin ${ }^{8}$ and strong odours such as petroleum, paint and nail varnish. ${ }^{9}$

About half of patients report migrainous features, such as photophobia or phonophobia with attacks, very often they lateralised to the side of the pain. ${ }^{510}$ Such 
patients usually have a personal or family history of migraine. Patients with both migraine and cluster headache are more likely to present with interictal dull pain, especially if using frequent sumatriptan dosing orally to treat attacks, ${ }^{11}$ which can be mistaken for hemicrania continua.

Cluster headache is more common in men, with a ratio of 2.5-3.5:1. However, it is important to recognise that women do present with cluster headache and there is often a delay to diagnosis. This may be because women tend to have more nausea and vomiting with their attacks ${ }^{12}$ and these symptoms are often attributed to migraine rather than cluster headache.

\section{DIFFERENTIAL DIAGNOSIS}

Cluster headache shares many features with the other trigeminal autonomic cephalalgias. The one that most closely resembles cluster headache is paroxysmal hemicrania; both conditions have a relatively short severe attack duration with overlap in their duration criteria. Paroxysmal hemicrania attacks are also unilateral and last 2-30 min, but the attacks are usually more frequent than in cluster headache. Paroxysmal hemicrania attacks can occur more than five times a day, ${ }^{1}$ up to 40 times a day, with a mean of $11 .^{13}$ They do not have the same nocturnal tendency as cluster headache and alcohol is not reliably a trigger. As complex as it makes the question, an absolute response to an adequate dose indomethacin is the sine qua non of $\mathrm{PH}$.

\section{INVESTIGATIONS}

Cluster headache is a primary headache disorder and thus, by definition, structural causes should not be present. One should consider a trigeminal autonomic cephalalgia to be secondary if the clinical presentation is not classical, if there is an atypical response to acute treatment, or if the headache does not respond to traditional preventives. In patients investigated for secondary cluster headache-like presentations, we recommend an MRI scan of the brain with gadolinium and pituitary function screening, specifically thyroid function tests, plasma prolactin and growth hormone/IGF1. This should be understood as a screen for secondary trigeminal autonomic cephalalgias in a generic sense. ${ }^{14}$ Pituitary tumours are relatively common $^{15} 16$ and their association with TAC-like headache ${ }^{17}$ complicates management.$^{18}$

\section{MANAGEMENT}

Management of cluster headache is broadly divided into acute and preventive; furthermore, there are novel neuromodulation devices that can be used for either (figure 1).
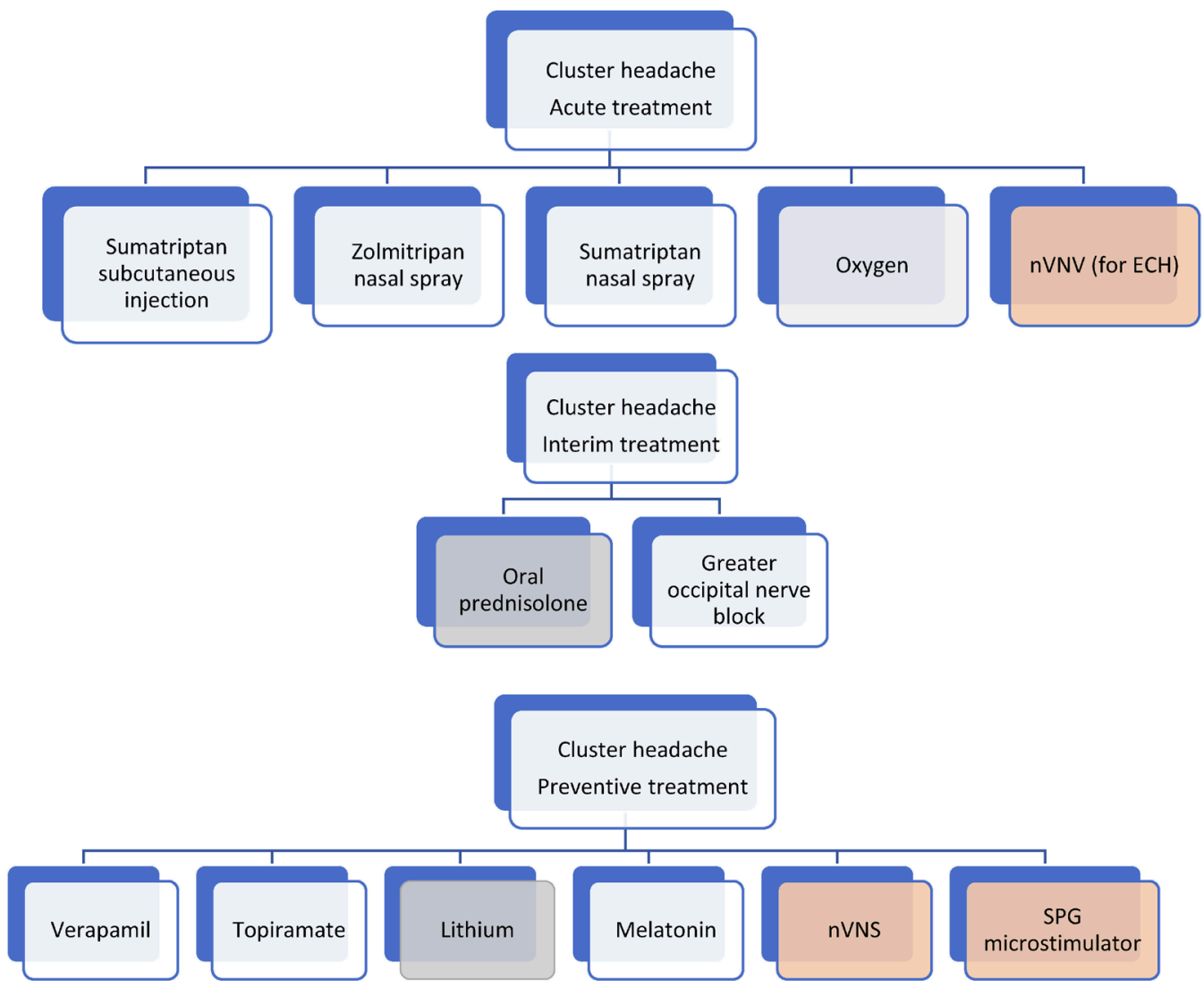

Figure 1 Current landscape for cluster headache treatment: the grey boxes indicate the medications that should be phased out, orange boxes indicate neuromodulation techniques. ECH, episodic cluster headache; nVNS, non-invasive vagus nerve stimulator; SPG, sphenopalatine ganglion. 
Table 1 Comparison of triptans in acute cluster headache treatment

\begin{tabular}{|c|c|c|}
\hline Triptan & Efficacy & Cost (as per BNF April 2019) \\
\hline $\begin{array}{l}\text { Subcutaneous } \\
\text { sumatriptan } 6 \mathrm{mg}\end{array}$ & $\begin{array}{l}\text { Headache relief rates at } 15 \text { min: placebo } 26 \% \text { and sumatriptan injection } \\
74 \%{ }^{19}\end{array}$ & $\begin{array}{l}\text { Imigran } \mathrm{f} 50.96 \text { for two injections } \\
\text { Generic } £ 39.50 \text { for two injections }\end{array}$ \\
\hline $\begin{array}{l}\text { Sumatriptan nasal spray } \\
20 \mathrm{mg}\end{array}$ & Pain-free rates at 30 min: placebo $18 \%$ and sumatriptan nasal spray $47 \%^{24}$ & Imigran $£ 14.16$ for two or $£ 42.47$ for six \\
\hline $\begin{array}{l}\text { Zolmitriptan nasal spray } \\
5 \mathrm{mg} \text { and } 10 \mathrm{mg}\end{array}$ & $\begin{array}{l}\text { Headache relief rates at } 30 \mathrm{~min} \text { (defined as reduction in pain severity): } \\
\text { placebo } 21 \% \text {; zolmitriptan nasal spray } 5 \mathrm{mg} 40 \% \text { and zolmitriptan nasal } \\
\text { spray } 10 \mathrm{mg} 62 \%{ }^{23}\end{array}$ & $\begin{array}{l}\text { Zomig } 5 \mathrm{mg} / 0.1 \mathrm{~mL} \text { nasal spray } 0.1 \mathrm{~mL} \\
\text { unit dose- } \mathrm{f} 36.50 \text { for six } \\
10 \mathrm{mg} \text { formulation-not available. }\end{array}$ \\
\hline
\end{tabular}

\section{Acute treatment for cluster headache attacks}

The evidence-based acute treatments for cluster headaches are subcutaneous sumatriptan, intranasal sumatriptan and zolmitriptan, high-flow oxygen via a non-rebreather mask and, in episodic cluster alone, non-invasive vagus nerve stimulation (nVNS). Double-blinded randomised control studies are effective in stopping attacks within 15 min have found the following for subcutaneous sumatriptan, high-flow oxygen via a non-rebreather mask and nVNS, ${ }^{19-22}$ and within $30 \mathrm{~min}$ for intranasal sumatriptan and zolmi$\operatorname{triptan}^{2324}$ (see table 1 for cost comparison). Oxygen is especially useful in patients who have more than two attacks a day, although is sometimes less convenient than sumatriptan. In the UK, prescribing oxygen prescription requires completion of a home oxygen order forms; part A is for static cylinders and part B is a restricted document for home oxygen assessment and review services, paediatric and other specialist teams and is used to order ambulatory oxygen. Before

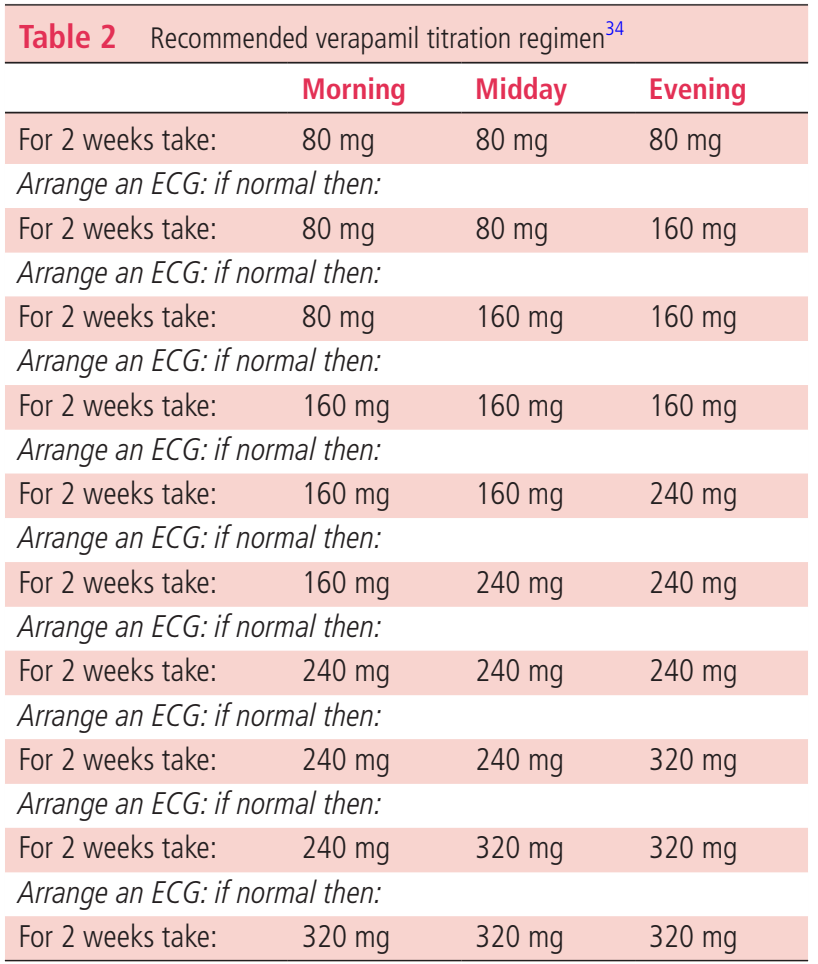

submitting the home oxygen order form part A, you must obtain patient consent using the initial home oxygen risk mitigation tool and home oxygen consent form.

\section{IS THE DEMAND-VALVE OXYGEN SYSTEM USEFUL?}

The demand-valve oxygen system has a valve that allows oxygen to flow when the patient inhales and closes after inhalation. The device has the benefit of supporting hyperventilation. In a single-blind, semirandomised, placebo controlled, crossover study, ${ }^{25}$ the primary end point of pain relief at 15 min was not significant, when compared with the simple mask and the $\mathrm{O}_{2}$ ptimask (a specialised non-rebreather mask with a $3 \mathrm{~L}$ reservoir, where dilution of oxygen is minimised). Patients, however, preferred the demand-valve oxygen system and one can argue lower oxygen consumption with it. While more research is clearly needed, many patients are very clear about its benefit and we see no downside to its use.

\section{Interim treatment options}

Patients may use interim measures while waiting for a preventive treatment to have therapeutic effect; such measures may also help patients with episodic cluster headache with short bouts. Although oral prednisolone is often used, this should be with caution given its long list of side effects and the cyclical pattern of cluster headache. Patients with episodic cluster headache require at least annual or biannual courses for a long period of time.

To avoid the cumulative side effects of corticosteroid, we prefer to perform a unilateral greater occipital nerve block, ${ }^{26-30}$ using $80 \mathrm{mg}$ of methylprednisolone with $2 \mathrm{~mL}$ of $2 \%$ lidocaine. This reduces frequency, severity of headaches, sometimes sufficient to carry patients through their bout. On average, the effects can last 4 weeks $^{26}$ and a greater occipital nerve injection can be repeated in 3 months.

\section{PREVENTIVE TREATMENT Verapamil}

Verapamil was found to be effective initially in an open-label study ${ }^{31}$ and subsequently in two randomised clinical trials. ${ }^{32} 33$ It is widely accepted as the first-line 

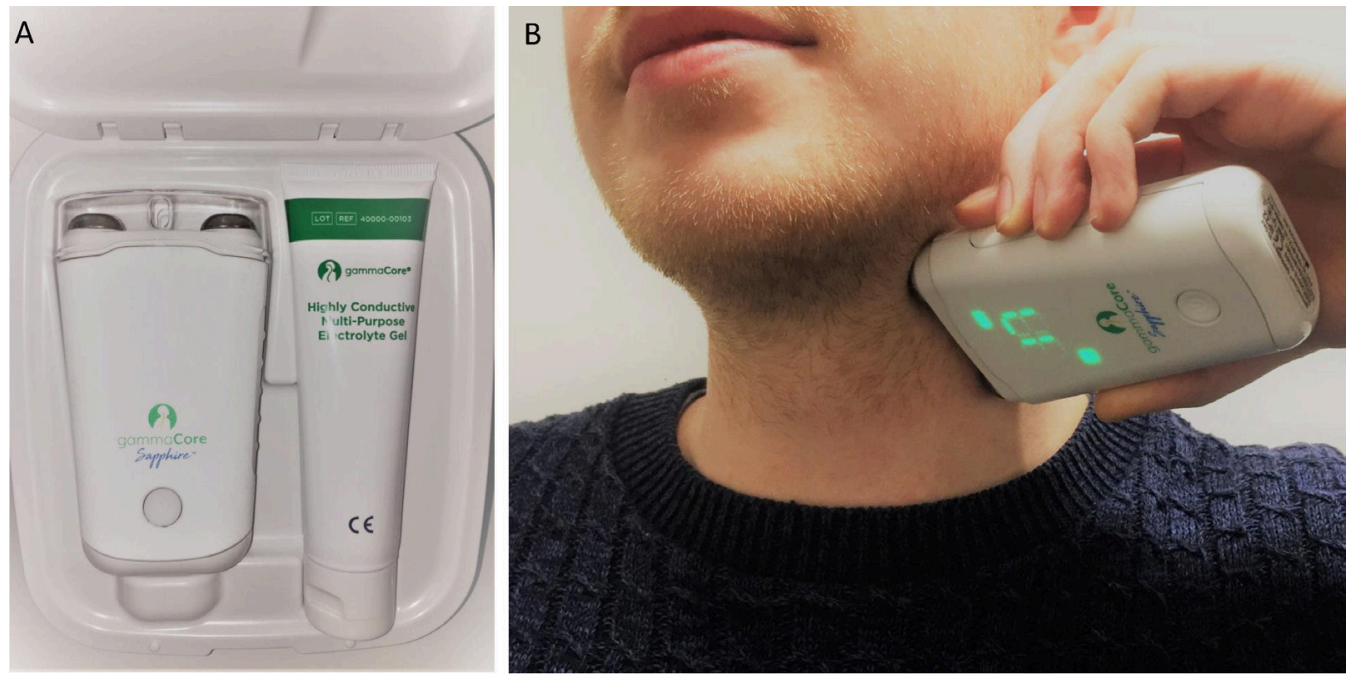

Figure 2 The gammaCore device (A) device shown with electrolyte gel and (B) device demonstration. Image published with permission of the individual.

preventive treatment for cluster headache, typically starting with $80 \mathrm{mg}$ three times a day with view to increasing it by $80 \mathrm{mg}$ every 2 weeks according to response; the maximum recommended dose is $320 \mathrm{mg}$ three times a day (see table 2).

Treating clinicians should aware that up to one in five patients taking verapamil develop cardiac arrhythmia, bradycardia or lengthening of the PR interval. ${ }^{34}$ Hence, it is recommended to perform a baseline 12-lead ECG before starting treatment, then at 10 days after each dose increment. After reaching a stable dose, ECGs should be checked once every 1-2 months and then every 6 months. There are reports of delayed onset of ECG abnormalities up to 2 years after being on a stable verapamil maintenance dose. ${ }^{35}$ Other less serious side effects to verapamil therapy include constipation and pedal oedema. ${ }^{34}$

Once a bout of cluster headache is over, the patient should withdraw verapamil cautiously to stop, with view to going straight on the effective dose of verapamil in the next cluster bout, provided the baseline ECG is normal. It is important not to keep patients
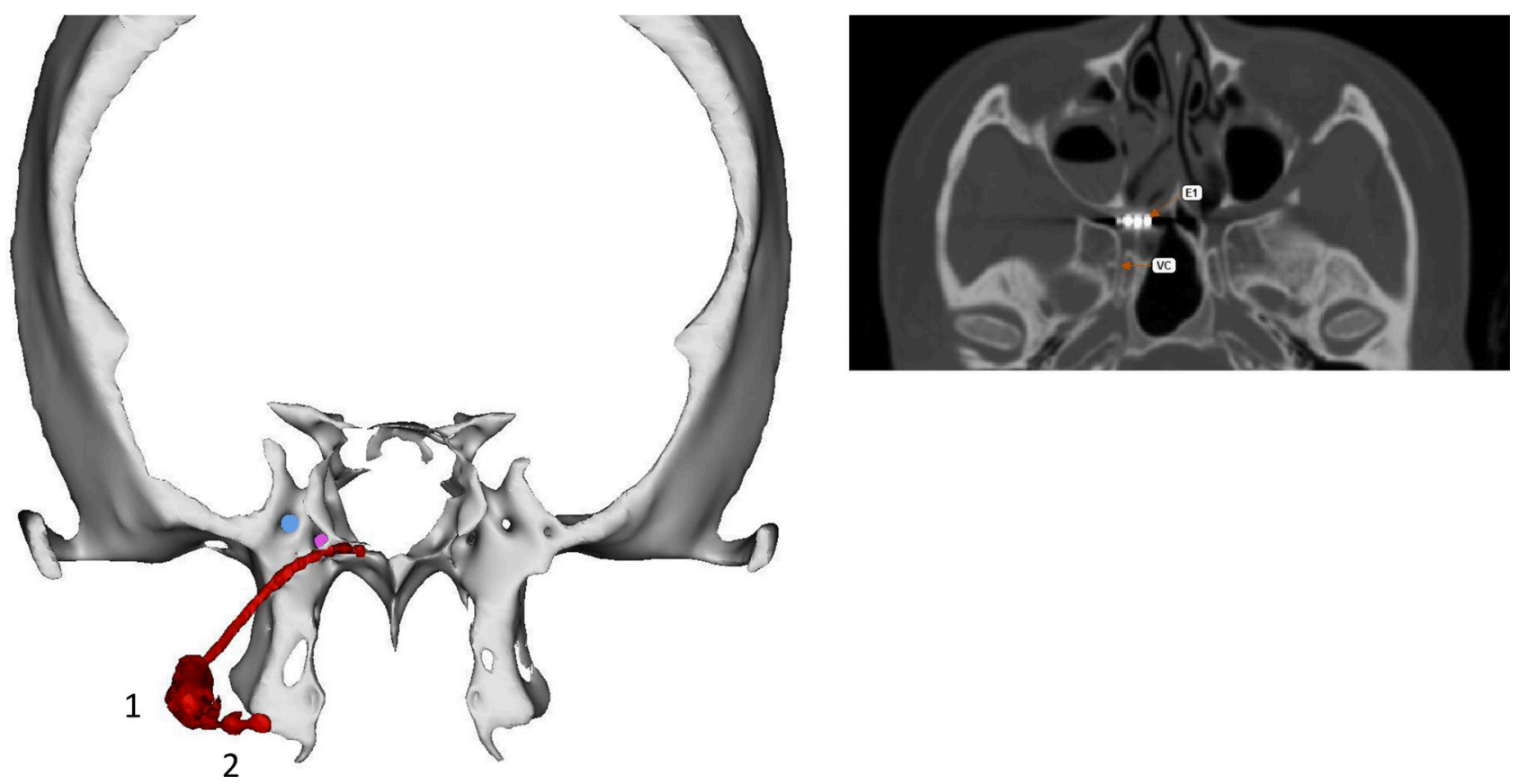

Figure 3 Right-sided SPG microstimulator from a patient in our centre. (A) Postoperative reconstructed CT scan of head, coronal view, showing the microstimulator in red, with electrode lead in the right pterygopalatine fossa, the body of the neurostimulator with the microprocessor and the RF-antenna (1) and the fixation plate (2), the pink indicates the vidian canal and the blue indicates foramen rotundum. (A) Axial view showing the relation of the VC and the first electrode of the microstimulator (E1). SPG, sphenopalatine ganglion; VC, vidian canal. 


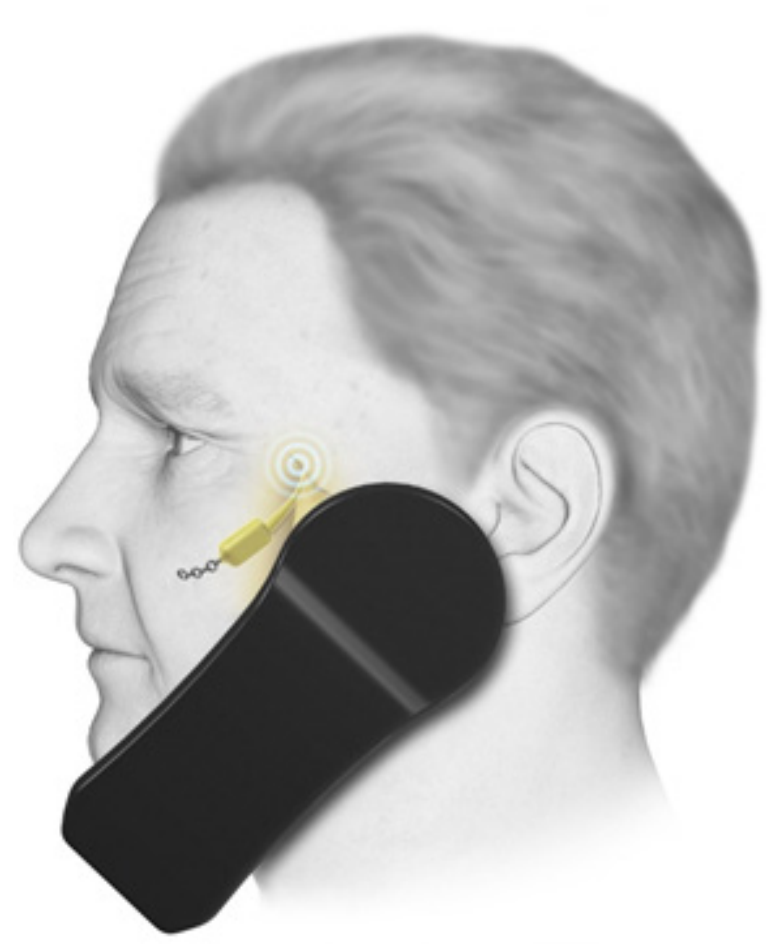

Figure 4 The SPG device and the remote controller. ${ }^{60}$ The patient activates the stimulator via a hand-held device which the patient puts on the cheek ipsilateral to the pain, the device should be held for $15 \mathrm{~min}$. Courtesy of Autonomic Technologies. SPG, sphenopalatine ganglion

on verapamil after their bout ends; anecdotally, we have found that this prolongs future bouts and there is a risk of tachyphylaxis.

\section{Lithium}

The evidence is limited for lithium ${ }^{33} 3637$ however it is generally accepted as a reasonable second-line option. It is more commonly used in chronic compared with episodic cluster headache but its potential impact on thyroid function and risk of interference with diuresis may complicate and limit its use. ${ }^{38}$ Lithium therapy requires regular blood monitoring to maintain a serum concentration between 0.4 and $1.2 \mathrm{mEq} / \mathrm{L}$, due to its narrow therapeutic index and potential risk of toxicity manifesting as a wide array of gastrointestinal and neurological symptoms. ${ }^{38}$

Lithium dosing starts at $300 \mathrm{mg}$ once a day, with weekly $300 \mathrm{mg}$ increments according to response, to a maximum dose of $1200 \mathrm{mg} /$ day; serum concentrations are best checked 12 hours after dosing; once the dose is stable and attacks controlled, serum lithium should be checked once every 1-2 months. ${ }^{38}$

\section{Melatonin}

There are many plausible theories to explain the potential link between melatonin and cluster headache attacks. ${ }^{39}$ Melatonin $10 \mathrm{mg}$ at night can help to prevent attacks of episodic cluster headache ${ }^{40}$ however, a trial of melatonin in chronic cluster headache ${ }^{41}$ could not reproduce that positive effect. However, one might argue that the formulation used or the timing of dosing might have been confounding factors.

Due to its tolerable side effect profile, melatonin is still widely used in preventing cluster headache, at doses between 10 and $25 \mathrm{mg}$ in the evening. ${ }^{42} 43$

\section{Topiramate}

The evidence for efficacy of topiramate in preventing cluster headache is limited to an open-label study using high doses (100-200 mg/day) with reported good efficacy in up to more than two thirds of patients. ${ }^{44}$

Side effects are major hurdle for topiramate use, in particular cognitive slowing, teratogenicity, nephrolithiasis and low mood as well as its potential effect on oral contraceptive efficacy, which can be a significant factor on preventive choice. ${ }^{45}$

\section{When to stop preventive therapy}

There is no clear guideline on how long to continue oral preventive therapy; it is generally accepted that preventive therapy should continue for up 4 weeks after attacks have settled, as evidenced by lack of 'shadows' or response to triggers, or after the usual length of the bout.

Patients' experience with their previous bouts can guide the decision to stop preventive therapy in episodic cluster headache. ${ }^{38}$ It is important to stop preventive treatment after each bout and not to have patients simply continue, given the wide range of side effects as well as the possibility of losing efficacy. When restarting a preventive such as verapamil for future bouts, there is usually no need to retitrate; provided the baseline ECG is normal, patients can be restarted at the dose that was effective for the last bout.

\section{NEUROMODULATION}

Neuromodulation is a useful development for treating cluster headache for patients in whom oral preventive therapy was either ineffective or contraindicated.

Given the data, we will focus on two neuromodulatory methods: nVNS and sphenopalatine ganglion (SPG) microstimulator.

\section{NON-INVASIVE VAGUS NERVE STIMULATION}

The gammaCore (nVNS) device (figure 2) has shown efficacy of using three 2 min ipsilateral stimulations of the cervical branch of the vagus nerve, in acute treatment for cluster headache attacks in an open-label study ${ }^{46}$ and has proven efficacy for the acute treatment in episodic cluster headache in two double-blind sham-controlled randomised studies. ${ }^{21}$ ${ }^{22}$ Similar attack treatment benefit was not found in chronic cluster headache, which may be related to high placebo response rate; a recent study has explained this observation by a modulatory effect on the trigeminalautonomic reflex by the sham device. ${ }^{47}$ 
The preventive effect of GammaCore was demonstrated in a prospective observational study in which almost $75 \%$ of patients showed overall improvement. ${ }^{46}$ There were similar results for chronic cluster headache in an open-label randomised trial using GammaCore as an adjunctive treatment ${ }^{48}$ using a unilateral, three 2 min stimulations, two times a day.

\section{Sphenopalatine ganglion microstimulator}

The SPG has been a target for different therapeutic options for a long time. However, an implantable small stimulator in the pterygopalatine fossa (figures 3 and 4) has shown efficacy for aborting acute cluster attacks in a randomised double-blind sham-controlled trial for medically refractory chronic cluster headache. ${ }^{49}$ The study found a preventive effect from SPG stimulation in a third of the patients enrolled, with an average of $83 \%$ attack frequency reduction compared with baseline in the long-term open-label follow-up. ${ }^{50}$ The second study, $\mathrm{CH}-2$, randomised 93 patients with chronic cluster headache $(1: 1)$ to sSPG stimulation or an active sham. The stimulation group had more pain relief and pain freedom at 15 min than the sham group, and again there was a preventive effect. ${ }^{51} \mathrm{~A}$ large European registry has reported the approach to be cost-effective over time. ${ }^{52}$ Our experience is in line with the clinical trials, that this treatment offers a way forward for a very disabled group of patients.

Like any other surgical procedure, the stimulator implantation comes with risks, the most common being sensory disturbances and postoperative pain and swelling, which were mild to moderate, and resolved within 2-3 months. ${ }^{53}$ The decision to proceed to surgery is best addressed via a multidisciplinary approach in a centre with the appropriate specialist expertise.

\section{Calcitonin gene-related peptide monoclonal antibodies}

Plasma calcitonin gene-related peptide is elevated in spontaneous and nitroglycerin-triggered cluster attacks while in bout. ${ }^{5455}$ In addition, its infusion can trigger attacks in patients with episodic cluster headache but only when in bout. ${ }^{56}$

To date, only galcanezumab has proven efficacy in reducing the number of weekly cluster headache attacks in episodic cluster headache in a placebocontrolled trial. ${ }^{57}$ The results were not replicated for chronic cluster headache. ${ }^{5859}$

\section{CONCLUSION}

Accurate diagnosis is key and the management of cluster headache is rapidly changing, with novel treatment options that are more specific to cluster headache.

Patients may find useful information on the UK patient group website: Organisation for the Understanding of Cluster Headache- OUCH(UK). https:// ouchuk.org/

\section{Key Points}

- Cluster headache is a debilitating headache disorder; early diagnosis allows appropriate treatment.

- Acute management of cluster headache is with sumatriptan subcutaneous injections and oxygen.

- Patients with atypical cluster headaches or those not responding to treatment should be investigated with MRI scan of brain with gadolinium and pituitary function testing.

- Aim to wean patients with episodic cluster headache off prophylaxis after the bout ends.

- There are novel and promising treatments for cluster headaches in the horizon.

Contributors DYW, PJG: conception, outline of article and final revisions. DYW, MK: first draft and revisions of manuscript.

Funding This paper represents independent research part funded by the National Institute for Health Research (NIHR) Biomedical Research Centre at South London and Maudsley

NHS Foundation Trust and King's College London. The views expressed are those of the authors and not necessarily those of the NHS, the NIHR or the Department of Health.

Competing interests PJG reports, over the last 36 months, grants and personal fees from Amgen and Eli-Lilly and Company, and personal fees from Alder Biopharmaceuticals, Allergan, Autonomic Technologies Inc., Biohaven

Pharmaceuticals Inc., Dr Reddy's Laboratories, Electrocore LLC, eNeura, Impel Neuropharma, MundiPharma, Novartis, Teva Pharmaceuticals, Trigemina Inc., WL Gore, and personal fees from MedicoLegal work, Massachusetts Medical Society, Up-to-Date, Oxford University Press, and Wolters Kluwer; and a patent magnetic stimulation for headache assigned to eNeura without fee.

\section{Patient consent for publication Not required.}

Provenance and peer review Commissioned. Externally peer reviewed by Nicola Giffin, Bath, UK and Alexandra Sinclair, Birmingham, UK.

Open access This is an open access article distributed in accordance with the Creative Commons Attribution Non Commercial (CC BY-NC 4.0) license, which permits others to distribute, remix, adapt, build upon this work noncommercially, and license their derivative works on different terms, provided the original work is properly cited, appropriate credit is given, any changes made indicated, and the use is noncommercial. See: http://creativecommons.org/licenses/by-nc/4. $0 /$.

\section{ORCID iDs}

Diana Y Wei http://orcid.org/0000-0003-0644-7172

Peter J Goadsby 0000-0003-3260-5904

\section{REFERENCES}

1 Headache Classification Committee of the International Headache Society (IHS). The International Classification of headache disorders, 3rd edition. Cephalalgia 2018;38:1-211.

2 Larner AJ. Trigeminal autonomic cephalalgias: frequency in a general neurology clinic setting. J Headache Pain 2008;9:325-6.

3 Bahra A, Goadsby PJ. Diagnostic delays and mis-management in cluster headache. Acta Neurol Scand 2004;109:175-9.

4 Schor L. Cluster headache: investigating severity of pain, suicidality, personal burden, access to effective treatment, and demographics among a large international survey sample. Cephalalgia 2017;37:172. 
5 Lai T-H, Fuh J-L, Wang S-J. Cranial autonomic symptoms in migraine: characteristics and comparison with cluster headache. J Neurol Neurosurg Psychiatry 2009;80:1116-9.

6 Bahra A, May A, Goadsby PJ. Cluster headache: a prospective clinical study with diagnostic implications. Neurology 2002;58:354-61.

7 Schürks M, Kurth T, de Jesus J, et al. Cluster headache: clinical presentation, lifestyle features, and medical treatment. Headache 2006;46:1246-54.

8 Ekbom K. Nitrolglycerin as a provocative agent in cluster headache. Arch Neurol 1968;19:487-93.

9 Nesbitt AD, Goadsby PJ. Cluster headache. BMJ 2012;344:e2407.

10 Irimia P, Cittadini E, Paemeleire K, et al. Unilateral photophobia or phonophobia in migraine compared with trigeminal autonomic cephalalgias. Cephalalgia 2008;28:626-30.

11 Paemeleire K, Bahra A, Evers S, et al. Medication-overuse headache in patients with cluster headache. Neurology 2006;67:109-13.

12 Rozen TD, Niknam RM, Shechter AL, et al. Cluster headache in women: clinical characteristics and comparison with cluster headache in men. J Neurol Neurosurg Psychiatry 2001;70:613-7.

13 Cittadini E, Matharu MS, Goadsby PJ. Paroxysmal hemicrania: a prospective clinical study of 31 cases. Brain 2008;131:1142-55.

14 Wilbrink LA, Ferrari MD, Kruit MC, et al. Neuroimaging in trigeminal autonomic cephalgias: when, how, and of what? Curr Opin Neurol 2009;22:247-53.

15 Agustsson TT, Baldvinsdottir T, Jonasson JG, et al. The epidemiology of pituitary adenomas in Iceland, 1955-2012: a nationwide population-based study. Eur J Endocrinol 2015;173:655-64.

16 Ezzat S, Asa SL, Couldwell WT, et al. The prevalence of pituitary adenomas: a systematic review. Cancer 2004;101:613-9.

17 Levy MJ, Matharu MS, Meeran K, et al. The clinical characteristics of headache in patients with pituitary tumours. Brain 2005;128:1921-30.

18 De Pue A, Lutin B, Paemeleire K. Chronic cluster headache and the pituitary gland. J Headache Pain 2016;17.

19 The Sumatriptan Cluster Headache Study Group. Treatment of acute cluster headache with sumatriptan. N Engl J Med Overseas Ed 1991;325:322-6.

20 Cohen AS, Burns B, Goadsby PJ. High-flow oxygen for treatment of cluster headache: a randomized trial. JAMA 2009;302:2451-7.

21 Silberstein SD, Mechtler LL, Kudrow DB, et al. Non-invasive vagus nerve stimulation for the acute treatment of cluster headache: findings from the randomized, double-blind, shamcontrolled ACT1 study. Headache 2016;56:1317-32.

22 Goadsby PJ, de Coo IF, Silver N, et al. Non-invasive vagus nerve stimulation for the acute treatment of episodic and chronic cluster headache: a randomized, double-blind, shamcontrolled ACT2 study. Cephalalgia 2018;38:959-69.

23 Cittadini E, May A, Straube A, et al. Effectiveness of intranasal zolmitriptan in acute cluster headache: a randomized, placebo-controlled, double-blind crossover study. Arch Neurol 2006;63:1537-42.

24 van Vliet JA, Bahra A, Martin V, et al. Intranasal sumatriptan in cluster headache: randomized placebo-controlled doubleblind study. Neurology 2003;60:630-3.
25 Petersen AS, Barloese MC, Lund NL, et al. Oxygen therapy for cluster headache. a mask comparison trial. a singleblinded, placebo-controlled, crossover study. Cephalalgia 2017;37:214-24.

26 Ambrosini A, Vandenheede M, Rossi P, et al. Suboccipital injection with a mixture of rapid- and long-acting steroids in cluster headache: a double-blind placebo-controlled study. Pain 2005;118:92-6.

27 Afridi SK, Shields KG, Bhola R, et al. Greater occipital nerve injection in primary headache syndromes - prolonged effects from a single injection. Pain 2006;122:126-9.

28 Leroux E, Valade D, Taifas I, et al. Suboccipital steroid injections for transitional treatment of patients with more than two cluster headache attacks per day: a randomised, double-blind, placebo-controlled trial. Lancet Neurol 2011;10:891-7.

29 Gantenbein AR, Lutz NJ, Riederer F, et al. Efficacy and safety of 121 injections of the greater occipital nerve in episodic and chronic cluster headache. Cephalalgia 2012;32:630-4.

30 Lambru G, Abu Bakar N, Stahlhut L, et al. Greater occipital nerve blocks in chronic cluster headache: a prospective openlabel study. Eur J Neurol 2014;21:338-43.

31 Gabai IJ, Spierings EL. Prophylactic treatment of cluster headache with verapamil. Headache 1989;29:167-8.

32 Leone M, D'Amico D, Frediani F, et al. Verapamil in the prophylaxis of episodic cluster headache: a double-blind study versus placebo. Neurology 2000;54:1382-5.

33 Bussone G, Leone M, Peccarisi C, et al. Double blind comparison of lithium and verapamil in cluster headache prophylaxis. Headache 1990;30:411-7.

34 Cohen AS, Matharu MS, Goadsby PJ. Electrocardiographic abnormalities in patients with cluster headache on verapamil therapy. Neurology 2007;69:668-75.

35 Lanteri-Minet M, Silhol F, Piano V, et al. Cardiac safety in cluster headache patients using the very high dose of verapamil ( $\geq 720 \mathrm{mg} /$ day). J Headache Pain 2011;12:173-6.

36 Ekbom K. Lithium for cluster headache: review of the literature and preliminary results of long-term treatment. Headache 1981;21:132-9.

37 Steiner TJ, Hering R, Couturier EG, et al. Double-blind placebo-controlled trial of lithium in episodic cluster headache. Cephalalgia 1997;17:673-5.

38 Becker WJ. Cluster headache: conventional pharmacological management. Headache 2013;53:1191-6.

39 Chazot G, Claustrat B, Brun J, et al. Effects on the patterns of melatonin and cortisol in cluster headache of a single administration of lithium at 7.00 P.M. daily over one week: a preliminary report. Pharmacopsychiatry 1987;20:222-3.

40 Leone M, D'Amico D, Moschiano F, et al. Melatonin versus placebo in the prophylaxis of cluster headache: a double-blind pilot study with parallel groups. Cephalalgia 1996;16:494-6.

41 Pringsheim T, Magnoux E, Dobson CF, et al. Melatonin as adjunctive therapy in the prophylaxis of cluster headache: a pilot study. Headache 2002;42:787-92.

42 Robbins MS, Starling AJ, Pringsheim TM, et al. Treatment of cluster headache: the American Headache Society evidencebased guidelines. Headache 2016;56:1093-106.

43 Gelfand AA, Goadsby PJ. The role of melatonin in the treatment of primary headache disorders. Headache 2016;56:1257-66.

44 Leone M, Dodick D, Rigamonti A, et al. Topiramate in cluster headache prophylaxis: an open trial. Cephalalgia 2003;23:1001-2. 
45 Pascual J, Láinez MJA, Dodick D, et al. Antiepileptic drugs for the treatment of chronic and episodic cluster headache: a review. Headache 2007;47:81-9.

46 Nesbitt AD, Marin JCA, Tompkins E, et al. Initial use of a novel noninvasive vagus nerve stimulator for cluster headache treatment. Neurology 2015;84:1249-53.

47 Shroeder CF, Möller M, May A. Vagus nerve stimulation modulates the cranial trigeminal-autonomic reflex - a comparison trial of different sham-conditions. Cephalalgia 2018;38(1 suppl):1-115.

48 Gaul C, Diener H-C, Silver N, et al. Non-invasive vagus nerve stimulation for prevention and acute treatment of chronic cluster headache (PREVA): a randomised controlled study. Cephalalgia 2016;36:534-46.

49 Schoenen J, Jensen RH, Lantéri-Minet M, et al. Stimulation of the sphenopalatine ganglion (SPG) for cluster headache treatment. pathway $\mathrm{CH}-1$ : a randomized, sham-controlled study. Cephalalgia 2013;33:816-30.

50 Jürgens TP, Barloese M, May A, et al. Long-term effectiveness of sphenopalatine ganglion stimulation for cluster headache. Cephalalgia 2017;37:423-34.

51 Goadsby PJ S-SS, Kezirian EJ, Calhoun AH, et al. Shamcontrolled study of sphenopalatine ganglion stimulation for chronic cluster headache. (Late-Breaking Abstract). Headache 2018;58:61-215.

52 Pietzsch JB, Weber SA, Lund N, et al. Changes in medication cost observed in chronic cluster headache patients treated with sphenopalatine ganglion (SPG) stimulation: analysis based on 1-year data from the pathway R-1 registry. Cephalalgia 2018;38:1455-62.
53 Barloese M, Petersen A, Stude P, et al. Sphenopalatine ganglion stimulation for cluster headache, results from a large, openlabel European registry. J Headache Pain 2018;19.

54 Goadsby PJ, Edvinsson L. Human in vivo evidence for trigeminovascular activation in cluster headache. neuropeptide changes and effects of acute attacks therapies. Brain 1994;117:427-34.

55 Fanciullacci M, Alessandri M, Figini M, et al. Increase in plasma calcitonin gene-related peptide from the extracerebral circulation during nitroglycerin-induced cluster headache attack. Pain 1995;60:119-23.

56 Vollesen ALH, Snoer A, Beske RP, et al. Effect of infusion of calcitonin gene-related peptide on cluster headache attacks: a randomized clinical trial. JAMA Neurol 2018;75:1187-97

57 Martinez JM GP, Dodick DW, Bardos JN, et al. Study CGAL: a placebo-controlled study of galcanezumab in patients with episodic cluster headache: results from the 8 -week doubleblind treatment phase. Cephalalgia 2018;38(1 suppl):145-6.

58 Clinicaltrials.org. A Study to Evaluate the Efficacy and Safety of TEV-48125 (Fremanezumab) for the Prevention of Episodic Cluster Headache (ECH) [online]. Available: https:// clinicaltrials.gov/ct2/show/NCT02945046 [Accessed 25 Sep 2018].

59 Clinicaltrials.org. A Study Comparing the Efficacy and Safety of TEV-48125 (Fremanezumab) for the Prevention of Chronic Cluster Headache (CCH) [online]. Available: https:// clinicaltrials.gov/ct2/show/NCT02964338 [Accessed 25 Sep 2018].

60 Technologies A. SPG-stimulator remote controller [online]. Available: http://www.ati-spg.com/us/en/ati-neurostimulationsystem/how-it-works/ [Accessed 25 Sep 2018]. 